\title{
Tradisi Ruwatan Wayang Bagi Umat Hindu Jawa
}

\author{
Oleh;
}

\author{
Poniman, S.Ag.,M.Fil.H
}

\begin{abstract}
:
The existence of wayang for Javanese society is something that has become a cultural tradition. The existence of the Wayang Tradition is evidenced by the continued emergence of dalang who perform wayang in certain areas with progressive artistic creativity. Wayang is a performance culture that is used as a medium or a means of transferring a particular science as well as entertainment. In the end, the function of wayang shows evolved from media guidance, spectacle, information delivery tools, to the promotion of certain products such as those that often appear on electronic glass screen media.
\end{abstract}

The existence of Wayang Kulit is a Javanese traditional art in particular, which is closely related to the levels of human life or the life cycle. Humans in their lives will be bound by the norms or value systems adopted by their society. The norms that are still valid in Javanese society include the Ruwatan ceremony which contains elements of salvation or cleansing humans from existing sin and calamity. Some people belonging to sukerta (dirty, sin) according to Javanese people's beliefs must be meruwat. Because if it is not diruwat it will become prey to Batara Kala. Then through Ruwatan by performing the wayang show Murwakala story and reading the Ruwatan mantras the Javanese people believe they will not be afraid and unlucky in their future lives.

Keywords :wayang, ruwatan ceremony.

\section{A. Pendahuluan}

Keberadaan wayang bagi masyarakat Jawa adalah merupakan sesuatu hal yang Sudah menjadi Tradisi budayanya. Adanya Tradisi Wayang tersebut dibuktikan dengan terus munculnya dalang-dalang yang mempergelarkan wayang di daerah-daerah tertentu dengan kreativitas seni yang progresif. Wayang merupakan suatu budaya pertunjukan yang digunakan sebagai media atau sarana mentransfer suatu ilmu tertentu disamping sebagai hiburan. Pada akhirnya fungsi pertunjukan wayang berkembang dari media tuntunan, tontonan, alat penyampai informasi, hingga media promosi suatu produk tertentu seperti yang sering muncul di media layar kaca elektronik. Wayang juga merupakan alat komunikasi dan sarana memahami kehidupan manusia. Dalam
Pertunjukan wayang kita tidak berhadapan dengan teori-teori umum, melainkan dengan model-model tentang hidup dan kelakuan manusia (Magnis Suseno, 1982: 7). Model-model tersebut merupakan hasil dari konsepsi yang tersusun menjadi sistem nilai budaya yang tersirat dalam pertunjukan wayang. Konsepsi tersebut antara lain adalah sikap dan pandangan terhadap hakikat kehidupan, asal-muasal dan tujuan hidup manusia, hubungan antara manusia dengan Tuhan-nya, hubungan antara manusia dengan lingkungannya, dan hubungan antara manusia dengan sesame manusia yang dikenal Tri Hita Karana.

Dinamika pewayangan dari jaman ke jaman mengalami perkembangan baik mencakup bentuk, teknik cerita, dan bahasanya. Dalam hal ini kita mengenal adanya wayang purwa/kulit, wayang 
madya, wayang, gedhog, wayang klithik, wayang dupara, wayang kancil, wayang beber, wayang Pancasila, wayang Budha, wayang wong sampai wayang berbahasa Indonesia. Keberadaan isi dari cerita dalam pewayangan-pun sering dikaitkan dengan peristiwa-peristiwa penting dalam kehidupan manusia atau perjalanan hidup manusia (rite de passage). Misalnya, dalam upacara perkawinan, selamatan kelahiran, tetesan, supitan, pindah rumah, bersih desa, dan lain-lain sampai ke ranah politik juga ada.

Hal tersebut disesuaikan dengan keperluan jamannya, maka dalam penyajian wayang biasanya menampilkan cerita yang dapat memberikan berkat atau mempunyai pengaruh terhadap peningkatan kesejahteraan hidup manusia. Misalnya dalam upacara perkawinan disajikan ceritera 'Parta Krama' (perkawinan Arjuna), cerita 'Laire Abimanyu' (Abimanyu Lahir) dalam upacara kelahiran, ceritera 'Baratayuda' dalam upacara bersih desa, ceritera 'Murwakala' dalam upacara ruwatan (pembersihan sukerta), dan sebagainya kesemuanya dibubuhi kreativitas seni yang semakin penuh dinamika.

Bersamaan dengan perkembangan jaman seperti sekarang yang ditandai adanya kemajuan ilmu pengetahuan dan teknologi yang serba mutakhir, serta pemikiran yang rasionalis, logis, namun dikalangan masyarakat Jawa kebiasaan dan keyakinan pembersihan dosa bagi orang yang nandang sukerta masih sering dilakukan. Upacara pembersihan dosa atau sukerta tersebut sering disebut dengan 'Ruwatan'. Pada upacara tersebut masyarakat Jawa biasa menyelenggarakan pergelaran wayang kulit dengan cerita 'Murwakala" ditambah dengan pembacaan mantra-mantra tertentu khususnya mantra untuk ruwatan oleh sang dalang. Namun selaras dengan perkembangan jaman tersebut pergelaran wayang kulit dengan lakon Murwakala tentunya juga mengalami perubahan berdasarkan kondisi, kebiasaan dan kepercayaan, serta teknik penyajiannya yang dilandasi kecerdasan sang dalangnya serta pendukung.

\section{B. Permasalahan}

Untuk pengembangan kebudayaan Wayang tersebut, kita tidak menutup diri, terbuka terhadap pengaruh budaya asing dengan dibarengi pula oleh kemajuan teknologi yang semakin pesat. Sejalan dengan hal tersebut penyerapan nilainilai budaya dari luar sering melupakan nilainilai lama yang mengakibatkan masyarakat sering kehilangan pegangan dalam menempuh arah dan tujuan hidup bermasyarakat, berbangsa, dan bernegara. Perongrongan terhadap warisan budaya tradisional menyebabkan pergeseran fundamental dibidang norma dan nilai (Notosusanto, 1984: 46). Dalam rangka proses pembangunan nasional (modernisasi) perlu memberikan makna pada nilai-nilai budaya yang lahir dan terkandung dalam kebudayaan lama agar tidak mengalami kepunahan. Adapun salah satunya adalah Ritual Ruwatan dengan pertunjukan wayang kulit yang relevan dengan pembangunan mentalitas khususnya, yaitu sebagai pegangan hidup bagi Umat Hindu. Hal ini sejalan dengan pakem Wayang yang bersumber dari kitab Itihasa yaitu Ramayana dan Mahabharata. Suatu unsur kebudayaan tidak akan bertahan lama jika tidak memiliki fungsi dan peran dalam masyarakat. Sebaliknya suatu unsur kebudayaan akan tetap bertahan apabila memiliki fungsi dalam kehidupan. Demikian pula upacara ruwatan dengan pertunjukan wayang kulit cerita murwakala dan unsur-unsur kebudayaannya tidak mungkin dipertahankan jika pendukungnya terutama Umat Hindu sudah tidak merasakan manfaatnya lagi yang merupakan kisah mahakarya bersumber dari Itihasa.

\section{Upacara Ruwatan}

Upacara Ruwatan sesungguhnya merupakan kebudayaan yang berasal dari jaman pra-Hindu, yaitu upacara penyembahan terhadap roh nenek moyang atau upacara inisiasi (Soedarsono, 1985: 12). Adapun ceritera Murwakala dan ruwatan di Jawa menurut Subalidinata (dalam Soedarsono, 1985: 3-48) bahwa pada semula berkembang 
di dalam cerita Jawa Kuna yang isi pokoknya memuat masalah penyucian, yaitu pembebasan dewa bernoda menjadi suci. Dengan kata lain dewa tersebut bernoda yang hidup sengsara dan dapat menjadi Dewa yang hidup bahagia setelah melalui tahap penyucian. Ngruwat berarti mengatasi atau menghindarkan suatu kesulitan batin (ngudari ruwet renteng) dengan jalan mengadakan pertunjukan wayang kulit dan mengambil cerita tertentu. Pada hakekatnya ruwatan merupakan suatu bentuk atau siasat mencapai kesenangan atau hiburan guna melupakan keruwetan batin (Sastroamidjaja, 1964: 145-163).

Beberapa orang yang harus diruwat menurut tradisi Jawa disebut sebagai orang sukerta (berada dalam dosa). Golongan sukerta tersebut kalau tidak diruwat maka hidupnya akan sengsara dan membahayakan lingkungan bahkan keluarganya. Orang-orang yang nandang sukerta tersebut menurut orang Jawa akan menjadi mangsanya (makanannya) Batara Kala, yaitu tokoh anak Batara Guru yang lahir karena nafsu yang tidak dapat dikendalikan. Ketika Batara Guru menginginkan untuk bersenggama pada senja hari, Dewi Uma menolak dan jatuhlah kama Batara Guru di tengah-tengah lautan hingga akhirnya menjadi raksasa. Dalam tradisi pewayangan hal itu disebut sebagai 'kama salah kendhang gumulung' . Raksasa tersebut kemudian menghadap ayahnya (Batara Guru) untuk minta makan. Batara Guru memberitahukan bahwa Kala boleh makan manusia yang termasuk dalam golongan wong sukerta atau manusia yang sial keberadaannya di dunia.

\section{Sumber Sastra Tentang Ruwatan}

Banyak karya sastra Jawa yang memuat ceritera tentang kelahiran Batara Kala dan wong sukerta, antara lain Kitab Parthayajna, Kitab Sudamala, Kitab Smaradahana, Kitab Kresna Kalantaka, Pakem Kandhaning Ringgit Purwa, serat Manikmaya, serat Centhini dan Pakem Pangruwatan Murwakala. Dalam kepustakaan
'Pakem Pangruwatan Murwakala' tersebut disebutkan mengenai 60 jenis kategori orang yang harus diruwat, antara lain:

1. Orang yang ketika menanak nasi, merobohkan dandang (tempat menanak nasi).

2. Memecahkan pipisan dan mematahkan gandhik (alat penggilas ramuan obat tradisional).

3. Uger-uger lawang, yaitu dua anak laki-laki dengan catatan tidak ada yang meninggal.

4. Anak bungkus, yaitu anak yang ketika lahir masih terbungkus oleh selaput pembungkus bayi (placenta).

5. Anak kembar, yaitu dua orang anak kembar putra atau putri atau kembar dhampit (satu laki-laki satunya perempuan) yang lahir bersamaan.

6. Kembang sepasang, atau sepasang bunga yaitu dua anak yang kedua-duanya perempuan.

7. Kedhana-kedhini, yaitu dua orang anak sekandung terdiri dari seorang seorang lakilaki dan seorang seorang perempuan.

8. Ontang-anting, yaitu anak tunggal laki-laki atau perempuan.

9. Sendhang kapit pancuran, yaitu tiga orang anak yang sulung dan bungsu laki-laki, sedang anak kedua perempuan.

10. Pancuran kapit sendhang, yaitu tiga orang anak yang sulung dan bungsu perempuan, sedang anak kedua laki-laki.

11. Saramba, yaitu empat orang anak semua lakilaki.

12. Srimpi, yaitu empat orang anak semua perempuan.

13. Mancala putra atau pandhawa, yaitu lima orang anak laki-laki.

14. Mancala putri atau pandhawi, yaitu lima orang anak perempuan.

15. Padhangan, yaitu lima orang anak terdiri dari empat orang laki-laki dan seorang perempuan.

16. Pipilan, yaitu lima orang anak yang terdiri 
empat orang perempuan dan seorang lakilaki.

17. Julung pujud, yaitu anak yang lahir pada saat matahari terbenam.

18. Julung sungsang, yaitu anak yang lahir tepat jam 12 siang.

19. Julung wang, yaitu anak yang lahir bersamaan dengan terbitnya matahari.

20. Tiba ungker, yaitu anak yang lahir kemudian meninggal.

21. Nyempina, yaitu anak yang baru berumur tujuh bulan dalam kandungan tetapi sudah lahir.

22. Tiba sampir, yaitu anak yang lahir berkalung usus.

23. Margana, yaitu anak yang lahir dalam perjalanan.

24. Wahana, yaitu anak yang lahir di halaman atau pekarangan rumah.

25. Siwah / salewah, yaitu anak yang dilahirkan memiliki dua macam warna, misalnya hitam dan putih.

26. Bule, yaitu anak yang dilahirkan berkulit dan berambut bule.

27. Kresna, yaitu anak yang dilahirkan berkulit hitam.

28. Walika, yaitu anak yang dilahirkan berwujud bajang (kerdil).

29. Wungkuk, yaitu anak yang dilahirkan dengan punggung bengkok.

30. Dengkok, yaitu anak yang dilahirkan punggungnya menonjol seperti punggung unta.

31. Lawang mengu, yaitu anak yang dilahirkan bersamaan dengan 'candhik ala' atau ketika warna langit merah kekuning-kuningan (sore hari).

32. Wujil, yaitu anak ytang lahir dengan badan cebol atau pendek.

33. Made, yaitu anak yang dilahirkan tanpa alas.

34. Orang yang bertempat tinggal di dalam rumah yang tak ada tutup keyongnya (atap).

35. Orang tidur diatas kasur tanpa sprei (penutup kasur).

36. Orang yang membuat pujingan (dekorasi) tanpa samir / daun pisang.

37. Orang yang memiliki lumbung (gudang) tempat penyimpanan padi tanpa diberi alas dan atap.

38. Orang yang menempatkan barang di suatu tempat (dandang misalnya) tanpa ada tempatnya.

39. Orang yang membuang kutu yang masih hidup.

40. Orang yang membuang kotoran / sampah dibawah tempat tidur (kolong).

41. Orang yang berdiri ditengah-tengah pintu.

42. Orang yang duduk didepan pintu.

43. Orang yang selalu bertopang dagu.

44. Orang yang gemar membakar kulit bawang.

45. Orang yang mengadu suatu wadah(misal, dandang dengan dandang).

46. Orang yang membakar / sedang membakar rambut.

47. Orang yang senang membakar tikar dari bambu (galar).

48. Orang yang senang membakar kayu pohon 'kelor'

49. Orang yang senang membakar tulang.

50. Orang yang senang menyapu sampah tanpa dibuang / dibakar sekaligus.

51. Orang yang membuang sampah lewat jendela.

52. Orang tidur pada waktu matahari terbit.

53. Orang tidur pada waktu matahari terbenam.

54. Orang yang memanjat pohon kelapa di siang haribolong (jam 12 siang).

55. Orang yang tidur waktu siang hari bolong (jam 12 siang).

56. Orang yang menanak nasi kemudian ditinggal pergi ke tetangga.

57. Orang yang suka mengakui hak orang lain. 
58. Orang yang suka meninggalkan beras di dalam lesung (tempat menumbuk padi).

59. Orang yang lengah sehingga merobohkan jemuran wijen / biji-bijian.

60. Orang yang suka membuang garam (mulyono, 1979: 34-36).

Demikianlah 60 jenis orang yang dijanjikan Batara Guru pada Batara Kala yang dapat dijadikan makanannya. Adapun lakon ruwatan yang sering dipergelarkan dalam wayng kulit adalah cerita Murwakala atau Purwakala atau sering disebut lakon Dalang Karurungan. Kata Purwa yang dapat diartikan sebagai purwaning dumadi atau asal mula kehidupan, asal mula kejadian manusia. Dikatakan Murwakala karena memuat penghayatan kejawen atas eksistensi manusia, adanya di duania beserta segala hal yang berakibat di dalamnya (Wirya Martono: 57). Dalam lakon ini yang menjadi titik pandangan manusia akan dirinya bukanlah manusia yang baik dan sempurna, melainkan keadaan manusia yang terlibat bencana atau salah kedaden. Keadaan demikian itu dipandang sebagai keadaan yang sukerta, kotor, sengsara, yang memerlukan peruwatan, pelepasan, pembersihan sehingga dapat mengantarkan ke alam sempurna. Dengan demikian manusia itu akan mampu mengarahkan kehidupannya dalam kedudukan sewajarnya.

\section{E. Adegan dalam Lakon Murwakala}

Garis besar cerita atau adegan yang dipentaskan pada upacara ruwatan adalah sebagai berikut:

1. Adegan di Kahyangan Batara Guru dengan Dewi Uma dihadap Narada, Panyarikan dan Hyang Kala. Setelah dijantur (dalang mendeskripsikan suasana dan keadaan di Jonggring Saloka), maka dialog dimulai. Inti pembicaraan adalah Kala mengutarakan tentang makanan yang dimakan membuatnya sakit perut, tetapi setelah memakan orang yang sedang mencari getah karet (nderes) yang jatuh ditanah tandus membuat badannya segar. Untuk itu Kala mohon ijin supaya diperbolehkan memakan manusia. Batara Guru memenuhi permintaan Kala dengan catatan boleh makan manusia tetapi hanya orang-orang yang termasuk kategori sukerta.

2. Kala bertemu dengan istrinya Batari Durga, memberitahukan mengenai permintaannya yang hanya diperbolehkan makan manusia golongan sukerta yang dicatat oleh Batara Panyarikan. Kemudian keduanya berangkat mencari mangsa.

3. Di Nguntaralaya Sang Hyang Wisnu, Hyang Brahma menerima kedatangan Resi Kanekaputra yang memberitahukan mengenai Kala yang diijinkan oleh Batara Guru untuk memakan manusia golongan sukerta. Maka Wisnu sebagai dewa pemelihara dunia, mengajak turun ke dunia dengan berubah wujud. Wisnu menyamar sebagai Dalang Kandhabuwana, Brahma menjadi penabuh gender dengan nama Penggender Saruni, dan Narada menjadi pengendang dengan nama Kalunglungan. Ketiga dewa itu turun menuju desa Mendang Kawit tempat kediamannya Nyai Randha Sumampir.

4. Kala, Durga dan Panyarikan dalam perjalanan yang melelahkan dengan naik gunung, masuk hutan dan sebagainya. Kala lelah dan tertidur dibawah pohon asam (kayu kamal). Kala kemudian melanjutkan perjalanannya lagi dan ketika tengah hari bertemu dengan Hyang Guru dan Dewi Uma yang sedang naik lembu Andini. Hyang Guru minta pada Kala supaya jangan ragu-ragu memangsanya. Namun sebelum memangsanya Kala harus dapat menjawab pertanyaan-pertanyaan yang diajukannya, antara lain:

"Apakah; Hong Eka, egul wancahe, dwi bogem, dwi purusa, dwi sregi, tri nabi sapta trisu". Kala tidak dapat menjawab pertanyaan itu, dan Guru menjelaskannya:

'Eka' satu dan egul itu ekor, ekornya lembu Andini adalah satu. Wancah itu lubang hidung 
dan lubang hidung Andini juga satu. 'Dwi' dua, 'bogem' adalah nama kelamin wanita yang berarti Andini mempunyai dua kelamin (purus). 'Dwi' dua, 'sregi' adalah tanduk, tanduk Andini ada dua. 'Tri' tiga, 'nabi' adalah pusar (udel), berarti pusarnya Guru, Uma dan Andini. 'Sapta' tujuh, 'trisu' adalah pandangan mata atau cahaya mata yang berarti pandangan mata Guru, Uma dan Andini ada tujuh dimana Guru mempunyai tiga mata. Asta $=$ tangan, catur $=$ empat, guto $=$ pelir, berarti tangannya Guru empat, catur guto berarti pelirnya Guru dan Andini adalah empat.

Demikian penjelasan Guru, setelah itu Guru memerintahkan agar memakan-nya, namun sebelum makan supaya melihat ke atas dahulu. Ternyata lewat tengah hari maka gagallah keinginan Kala. Setelah itu Guru berpesan kepada Kala agar berhati-hati terhadap orang yang dapat mengerti/ tahu apa yang dititipkan Guru pada Kala, yakni; caraka balik pada dahi, sastra telak pada kedua langit-langit mulutnya, sastra pedati yang berada pada dada, sastra gigir pada punggung. Jika ada orang yang mengetahui seluk beluk apa yang ada pada badan Kala, agar ia taat dan patuh terhadap segala yang diperintahkannya. Setelah memberikan pesan, maka pergilah Batara Guru.

1. Di Mendang Gati Nyi Randha merasa prihatin dengan anak tunggalnya yang bernama Jatusmati Jaka Mulya. Pada suatu hari Nyi Randha menerima ilham dari dewa bahwa anaknya dapat lepas dari dosa (sukerta) jikalau mandi di telaga Madirda. Maka Nyi Randha membujuk anaknya dan Jaka Mulya-pun melaksanakan perintah tersebut. Sesampainya di telaga tersebut kemudian Jatusmati masuk ke dalam telaga, dan ternyata Kala sudah lebih dulu ada dan berendam di telaga tersebut. Kala bertanya mengenai maksud Jatusmati merendam di telaga itu. Jaka Mulya menjawab bahwa ia anak ontanganting dan atas perintah ibunya supaya mandi di telaga itu untuk menghilangkan dosa yang ada pada dirinya. Kala sangat gembira maka berkatalah: "Dosamu akan hilang bersama nyawamu (jiwamu) untuk itu lebih baik kau kumakan" Mendengar itu, maka Jatusmati lari namun Kala mengikuti dan mengejar kemana Jatusmati lari. Dalam pelarian itu Jatusmati berusaha bersembunyi antara lain pada bambu yang berlubang, masuk pada tempat orang yang sedang membangun rumah yang belum ada tutup keyongnya (atap) dan rumah itu roboh. Ketika Jatusmati mendekati orang yang sedang meramu jamu dan diketahui Kala, maka ditangkaplah Jatusmati namun gagal dan tempat meramu obat itu patah. Jatusmati kemudian lari masuk rumah dan berada disamping tempat menanak nasi (dandang), Kala menangkapnya tapi luput dan dandang itu roboh. Demikianlah, maka setiap orang yang mengalami peristiwa tersebut harus diruwat.

2. Di Mendang Tamtu, Buyut Wangkeng menerima putra menantu Rara Primpen dan suaminya yang bernama Joko Sondong atau Buyut Geduwal. Buyut Geduwal memberitahukan kepada Buyut Wangkeng bahwa perkawinannya tidak bahagia sehingga keduanya belum melakukan hubungan layaknya suami istri. Atas petunjuk Buyut Wangkeng, maka Joko Sondong diminta pergi ke Mendang Kawit menemui Dalang Kandhabuwana dan memintanya supaya mempergelarkan wayang di Mendang Tamtu.

3. Di Mendang Kawit, Nyi Randha Sumampir berbincang-bincang dengan Dalang Kandhabuwana, pemain gender Nyi Saruni, dan pemain kendhang Kyai Kalunglungan yang bertempat tinggal di rumahnya. Nyi Randha mengatakan bahwa selama rombongan itu tinggal di rumahnya desa Mendang Kawit menjadi tentram aman dan sejahtera. Maka Nyi Randha 
menyampaikan ucapan terima kasih dan selanjutnya dalang Kandhabuwana mengganti nama Nyi Randha Sumampir dengan nama Randha Asem Sore serta memberikan bermacam-macam petuah kepada NyiAsem Sore. Setelah itu datanglah Buyut Geduwal menghadap Dalang Kandhabuwana dan memberitahukan maksudnya untuk memintanya supaya mempergelarkan wayang kulit di Mendang Tamtu. Permintaannya disanggupi dan berangkatlah mereka ke Mendang Tamtu dengan membawa peralatan gamelan.

4. Buyut Wangkeng di Mendang Tamtu menerima Dalang Kandhabuwana dan rombongannya. Buyut wangkeng mengutarakan niatnya untuk meruwat Rara Primpen yang tidak bahagia dalam perkawinannya. Maka dalang Kandhabuwana mulai mempergelarkan wayang kulit dengan cerita Murwa Kala. Pergelaran wayang itu menarik perhatian penonton dan pada pertengahan pertunjukan wayang datanglah Jatusmati yang lari dikejar-kejar oleh Kala. Jatusmati masuk dalam rombongan penabuh gamelan dan ia menabuh kethuk. Ketika Kala sampai pada tempat pergelaran wayang itu, Kala berhenti dan bersandar pada pohon kelapa. Kala tertarik dan terpingkalpingkal oleh humor yang ditampilkan oleh sang dhalang. Mendengar tawa Kala, penonton takut dan meninggalkan tempat itu sehingga pergelaran wayang terhenti. Kala meminta supaya pergelaran itu dilanjutkan dan terjadilah dialog antara Dalang Kandhabuwana dan Batara Kala. Jika dilanjutkan Kala akan memberikan hadiah uang pada Ki Dalang, namun Kandhabuwana menolak dan meminta upah yang dibawa Kala saja. Yaitu Bedama Paesan, dan Kala-pun memberikannya. Dalang Kandhabuwana kemudian melanjutkan pergelaran wayangnya lagi, namun tiba-tiba datanglah empat pencuri yang melarikan diri dan masuk tempat penabuh gamelan ikut memainkan kecer dan kempyang. Sementara itu Kala mengantuk dan mulutnya menganga, ketika dilempar telor ayam oleh Ki Dalang ia terbangun dan merasa segar kembali. Karena sudah pagi dan takut ketahuan orang maka Kala pamit untuk pergi dari tempat itu. Ketika pergi Kala mendengar tangis bayi yang sedang dilahirkan, dan Kala segera mendekat lalu ditangkapnya. Jatusmati tahu jika Kala sudah pergi, maka iapun keluar dari tempat itu. Ketika sampai diluar ia bertemu Kala dan iapun ditangkapnya. Pada waktu akan memakan mangsanya, ia teringat senjata bedama paesan yang diberikannya pada Ki Dalang. Kala segera menemui Ki Dalang dan meminta senjatanya kembali. Ki Dalang mau menyerahkan asal ia juga menyerahkan bayi dan Jatusmati yang ditangkapnya itu. Dan terjadilah tukarmenukar serta dialog antara Kala dengan Ki Dalang. Dalam dialog itu Dalang Kandhabuwana menanyakan siapa yang lebih tua antara Kala dan Ki Dalang. Karena mengetahui asal-usulnya maka Kala merasa ialah yang lebih tua. Kemudian Ki Dalang menjelaskan kepada Kala dengan beberapa mantram (doa) dengan urutan; (1) Jantur Wa Kala Mur, (2) Sampurnaning Puja, (3) Santi Purwa, (4) membaca caraka balik, yakni huruf di dahi, (5) membaca satra telak, yakni huruf di langit-langit mulut, (6) membaca sastra pinedati, yakni huruf di dada, (7) membaca sastra trusing gigir, yakni huruf di punggung, (8) Santi Kukus, (9) Bala Srewu, (10) Banyak Dhalang, (11) Wisikaning Kala, (12) Padusaning Kala, (13) Kudanganing Kala, (14) Kumbala Geni, (15) Padusan Jatusmati, (16) Padusan Dhalang lan Panjak, (17) Sumbar, (18) Sebet. 
Dengan demikian maka selesailah upacara ruwatan.

\section{F. Mantram dalam Upacara Ruwatan}

Mantram atau mantra merupakan aspek yang terpenting dalam upacara ruwatan. Mantra dapat diartikan sebagai perkataan atau kalimat yang dapat mendatangkan daya ghaib. Mantra yang diiringi dengan bunyi-bunyian aatau alat musik menurut masyarakat pendukungnya akan mampu membersihkan dosa seseorang yang akhirnya kembali menjadi suci seperti manusia lainnya. Itulah sebabnya setiap upacara ruwatan pembacaan mantram merupakan hal yang pokok dan sakral.

Ada berbagai macam versi mantram dalam upacara ruwatan. Namun babon pangruwatan yang sering digunakan oleh para dalang adalah Murwakala, menurut babon pedhalangan Kyai Panjangmas seperti yang ditulis dalam Cebolang atau Suluk Tambangraras pada jaman Paku Buwana V (1820 - 1823) di Surakarta. Dalam serat Cebolang itu menyebutkan jumlah mantram yang diucapkan oleh Ki Dalang terdiri dari 13 macam. Dari berbagai versi mantra ruwatan, mantra pokok yang harus diucapkan adalah; sastra dahi (caraka balik), sastra pedati (sastra dada), sastra telak, dan sastra gigir.

Dibawah ini contoh cuplikan mantram Pangruwatan Wayang :

\section{Awighnam astu namas idem}

Kala awang-awang ana bumi langit, nanging Sang Hjang Wisesa ingkang kotjap sarta djumeneng samadi satengahing djagad. Sang Hjang Wisesa mireng swara kadi genta, sarta anon tigan, gumantung neng awang-awang, sinangga ngasta pinusti dadi telung prakara, saprakara dadi bumi langit, rong prakarane dadi tedja lan tjahja, katigane Manik Maja. Mangka Manik dadi papat. Mangka papat iku ming Batara Guru uger-ugere, kang pinangka gegentene Sang Hjang Wisesa, Winenang andadekake isining bumi, sarta Winesik saliring Wadi.

Mangka sasirnaning (samuksane) Sang Hjang Wisesa, Batara Guru akarja tetimbangan garwa wasta Dewi Uma, nunten ajoga para dewa 30 lan sarta sadjodone. Nunten bumi pisah lan akasa. Hjang Pramesti nunten amatah dewa nawa sanga amrih djedjeging bumi, sarta gunung Djamurdipa wus warata. Nunten Batara Guru ajasa kahjangan lan kaswargan, lan saisine. Mangka Sang Hjang Pramesti anjatekaken djenenging lanang lan wadon, lan garwa Dewi Uma, reta kerut tan ketadhahan, mila wonten Batara Kala Hjang Pramesti adeduka mring garwa Dewi Uma, mila wonten Batari Durga djodo lan Kala. Nunten Hjang Guru anitahaken redjaki Martjapada Mendang Kamulan. Mila Batara kala minggah mring Suralaya saputra garwa balane.

\section{G. Penutup}

Keberadaan Wayang Kulit merupakan seni tradisional Jawa khususnya, yang erat hubungannya dengan tingkatan-tingkatan hidup manusia atau daur hidup. Manusia dalam hidupnya akan terikat dengan norma-norma atau sistem nilai yang dianut oleh masyarakatnya. Adapun norma yang masih berlaku di masyarakat Jawa antara lain upacara ruwatan yang mengandung unsurunsur penyelamatan atau pembersihan manusia dari dosa dan malapetaka yang ada.

Beberapa Orang yang tergolong dalam sukerta (kotor, dosa) menurut kepercayaan masyarakat Jawa harus diruwat. Sebab kalau tidak diruwat akan menjadi mangsanya Batara Kala. Maka melalui ruwatan dengan mempergelarkan wayang kulit cerita Murwakala dan pembacaan mantra-mantra ruwatan masyarakat Jawa percaya tidak akan takut dan sial dalam kehidupannya kelak.

\section{DAFTAR PUSTAKA}

Ismunandar. Wayang Asal-usul dan Jenisnya. Daharo-Prize

Martono, Kuntara Wirya. Dari Sudut-sudut 
Filsafat Sebuah Bunga Rampai.

Mulyono, Sri. Simbolisme dan Mikstikisme dalam Wayang. Jakarta

Notosusanto, Nugraha. 1984. Menegakkan Wawasan Almamater. UI-Pres

Sastraamidjojo, sena. 1964. Renungan tentang Pertunjukan Wayang Kulit. Jakarta: Kinta

Suseno, Franz Magnis. 1982. Kita dan Wayang. Jakarta: Leppenas

Soedarsono. 1985. Peranan seni budaya dalam sejarah Kehidupan Manusia Kontinuitas dan Perubahannya. UGM

Tanojo dan Kyai demang Reditaya. Pakem Pangruwatan Murwakala 